\title{
Determination of Fire Resistance of Eccentrically Loaded Reinforced Concrete Columns Using Fuzzy Neural Networks
}

\author{
Marijana Lazarevska $\mathbb{D}^{1},{ }^{1}$ Ana Trombeva Gavriloska, ${ }^{2}$ Mirjana Laban, ${ }^{3}$ Milos Knezevic $\mathbb{D}^{4}{ }^{4}$ \\ and Meri Cvetkovska ${ }^{1}$
}

${ }^{1}$ Faculty of Civil Engineering, University Ss Cyril and Methodius, 1000 Skopje, Macedonia

${ }^{2}$ Faculty of Architecture, University Ss Cyril and Methodius, 1000 Skopje, Macedonia

${ }^{3}$ Faculty of Technical Sciences, University of Novi Sad, Novi Sad, Serbia

${ }^{4}$ Faculty of Civil Engineering, University of Montenegro, 81000 Podgorica, Montenegro

Correspondence should be addressed to Marijana Lazarevska; marijana@gf.ukim.edu.mk

Received 21 February 2018; Accepted 8 July 2018; Published 23 August 2018

Academic Editor: Matilde Santos

Copyright ( 2018 Marijana Lazarevska et al. This is an open access article distributed under the Creative Commons Attribution License, which permits unrestricted use, distribution, and reproduction in any medium, provided the original work is properly cited.

\begin{abstract}
Artificial neural networks, in interaction with fuzzy logic, genetic algorithms, and fuzzy neural networks, represent an example of a modern interdisciplinary field, especially when it comes to solving certain types of engineering problems that could not be solved using traditional modeling methods and statistical methods. They represent a modern trend in practical developments within the prognostic modeling field and, with acceptable limitations, enjoy a generally recognized perspective for application in construction. Results obtained from numerical analysis, which includes analysis of the behavior of reinforced concrete elements and linear structures exposed to actions of standard fire, were used for the development of a prognostic model with the application of fuzzy neural networks. As fire resistance directly affects the functionality and safety of structures, the significance which new methods and computational tools have on enabling quick, easy, and simple prognosis of the same is quite clear. This paper will consider the application of fuzzy neural networks by creating prognostic models for determining fire resistance of eccentrically loaded reinforced concrete columns.
\end{abstract}

\section{Introduction}

The fire resistance of civil engineering structures can be determined based on the estimated fire resistance of each construction element (columns, beams, slabs, walls, etc.). The fire resistance of a structural element is the time period (in minutes) from the start of the fire until the moment when the element reaches its ultimate capacity (ultimate strength, stability, and deformability) or until the element loses the insulation and its separation function [1]. The legally prescribed values for the fire resistance can be achieved by application of various measures (by using appropriate shape and element's dimensions and proper static system, thermoisolation, etc.). The type of applied protection measures mainly depend on the type of construction material that needs to be protected. Different construction materials (concrete, steel, and wood) have different behaviors under elevated temperatures. That is why they have to be protected in accordance with their individual characteristics when exposed to fire [1]. Even though the legally prescribed values of the fire resistance is of huge importance for the safety of every engineering structures, in Macedonia there is no explicit legally binding regulation for the fire resistance. The official national codes in the Republic of Macedonia are not being upgraded, and the establishment of new codes is still a continuing process. Furthermore, most of the experimental models for determination of fire resistance are extremely expensive, and analytical models are quite complicated and time-consuming. A modern type of analyses, such as modeling through neural networks, can be very helpful, particularly in those cases where some prior analyses were already made. Therefore, the application of artificial and 
fuzzy neural networks for prognostic modeling of the fire resistance of structures is of significant importance, especially during the design phase of civil engineering structures.

Fuzzy neural networks are typical example of a modern interdisciplinary subject that helps solving different engineering problems which cannot be solved by the traditional modeling methods [2-4]. They are capable of collecting, memorizing, analyzing, and processing large number of data obtained from some experiments or numerical analyses. The trained fuzzy neural network serves as an analytical tool for precise predictions, for any input data which are not included in the training or testing process of the model. Their operation is reasonably simple and easy, yet correct and precise.

Using the concept of the fuzzy neural networks and the results of the performed numerical analyses (as input parameters), the prediction model for defining the fire resistance of eccentrically loaded RC columns incorporated in walls and exposed to standard fire from one side has been made.

The goal of the research presented in this paper was to build a prognostic model which could generate outputs for the fire resistance of RC columns incorporated in walls, for any given input data, by using the results from the conducted numerical analyses. The numerical results were used as input data in order to create and train the fuzzy neural network so it can provide precise outputs for the fire resistance of eccentrically loaded RC columns for any other input data (RC columns with different dimensions of the cross section, different thickness of the protective concrete layer, different percentage of reinforcement, and for different loads).

\section{Fuzzy Neural Networks: Theoretical Basis}

Fuzzy neural networks are defined as a combination of artificial neural networks and fuzzy systems, in such a way that learning algorithms from neural networks are used to determine the parameters of a fuzzy system. One of the most important aspects of this combination is that the system can always be interpreted using the "if-then" rule, because it is based on a fuzzy system that reflects uncertain/unclear knowledge. Fuzzy neural networks use linguistic knowledge from the fuzzy system and learning ability from neural networks. Therefore, fuzzy neural networks are capable of precisely modeling ambiguity, imprecision, and uncertainty of data, with the additional learning opportunity characteristic of neural networks $[3,5-8]$.

Fuzzy neural networks are based on a common concept of fuzzy logic and artificial neural networks, theories that are already at the top of the list for researchers of artificial intelligence. Fuzzy logic, based on Zadeh's principle of fuzzy sets, provides mathematical potential for describing the uncertainty that is associated with cognitive processes of thinking and reasoning. This makes it possible to draw conclusions even with incomplete and insufficiently precise information (so-called approximate conclusions). On the other hand, artificial neural networks with their various architectures built on the artificial neuron concept have been developed as an imitation of the biological neural system for the successful performance of learning and recognition functions. What is expected from the fusion of these two structures is that the learning and computational ability of neural networks will be transmitted into the fuzzy system and that the highly productive if-then thinking of the fuzzy system will be transferred to neural networks. This would allow neural networks to be more than simply "black boxes," while fuzzy inference systems will be given the opportunity to automatically adjust their parameters $[2,3,5-8]$.

Depending on the field of application, several approaches have been developed for connecting artificial neural networks and fuzzy inference systems, which are most often classified into the following three groups [3, 5, 7-9]: cooperative models, concurrent models, and integrated (hybrid) models.

The basic characteristic of the cooperative model is that via learning mechanisms of artificial neural networks, parameters of the fuzzy inference system are determined through training data, which allows for its quick adaption to the problem at hand. A neural network is used to determine the membership function of the fuzzy system, the parameters for fuzzy rules, weight coefficients, and other necessary parameters. Fuzzy rules are usually determined using clustering access (self-organizing), while membership functions are elicited from training data using a neural network [3, 5, 7-9].

Characteristic of the concurrent model is that the neural network continuously assists the fuzzy inference system during the process of determining and adjusting required parameters. In some cases, the neural network can correct output results, while in other cases, it corrects input data into the fuzzy inference system $[3,5,7-9]$.

For integrated fuzzy neural networks, the learning algorithm from a neural network is used to determine the parameters of the fuzzy inference system. These networks represent a modern class of fuzzy neural networks characterized by a homogeneous structure, that is, they can be understood as neural networks represented by fuzzy parameters [3, 5-9]. Different models for hybrid fuzzy neural networks have been developed, among which the following stand out: FALCON, ANFIS, GARIC, NEFCON, FUN, SONFIN, FINEST, and EFuNN.

\section{State-of-the-Art Application of Fuzzy Neural Networks}

In the civil engineering field, fuzzy neural networks are very often used to predict the behavior of materials and constructive elements. The main goal of such prognostic models is to obtain a solution to a problem by prediction (mapping input variables into corresponding output values). For the qualitative development of efficient prognostic models, it is necessary to have a number of data groups. Fortunately, when it comes to civil engineering, data collection is not a major problem, which enhances the possibility of applying such innovative techniques and methods. Some examples of successful application of fuzzy neural networks to various fields of civil engineering are presented in the following section of this paper $[4,5]$.

Fuzzy neural networks have enjoyed successful implementation in civil engineering project management. Boussabaine and Elhag [10] developed a fuzzy neural 
network for predicting the duration and cost of construction works. Yu and Skibniewski (1999) investigated the application of fuzzy neural networks and genetic algorithms in civil engineering. They developed a methodology for the automatic collection of experiential data and for detecting factors that adversely affect building technology [11]. Lam et al. [12] successfully applied the principles of fuzzy neural networks towards creating techniques for modeling uncertainty, risk, and subjectivity when selecting contractors for the construction works. Ko and Cheng [13] developed an evolutionary fuzzy neural inference model which facilitates decisionmaking during construction project management. They tested this model using several practical examples: during the selection of subcontractors for construction works and for calculating the duration of partition wall construction, an activity that has an excessive impact on the completion of the entire project. Jassbi and Khanmohammadi applied ANFIS to risk management [14]. Cheng et al. proposed an improved hybrid fuzzy neural network for calculating the initial cost of construction works [15]. Rashidi et al. [16] applied fuzzy neural systems to the selection of project managers for construction projects. Mehdi and Reza [17] analyzed the application of ANFIS for determining risks in construction projects, as well as for the development of intelligent systems for their assessment. Feng and Zhu [18] developed a model of self-organizing fuzzy neural networks for calculating construction project costs. Feylizadeh et al. [19] used a model of fuzzy neural networks to calculate completion time for construction works and to accurately predict different situations.

Fuzzy neural networks are also used for an analysis of structural elements and structures. Ramu and Johnson applied the approach of integrating neural networks and fuzzy logic for assessing the damage to composite structures [20]. Liu and Wei-guo (2004) investigated the application of fuzzy neural networks towards assessing the safety of bridges [21]. Foncesa used a fuzzy neural system to predict and classify the behavior of girders loaded with concentrated loads [22]. Wang and Liu [23] carried out a risk assessment in bridge structures using ANFIS. Jakubek [24] analyzed the application of fuzzy neural networks for modeling building materials and the behavior of structures. The research encompassed an analysis of three problems: prediction of fracture in concrete during fatigue, prediction of high performance concrete strength, and prediction of critical axial stress for eccentrically loaded reinforced concrete columns. Tarighat [25] developed a fuzzy neural system for assessing risk and damage to bridge structures, which allows important information to be predicted related to the impact of design solutions on bridge deterioration. Mohammed [26] analyzed the application of fuzzy neural networks in order to predict the shear strength of ferrocement elements and concrete girders reinforced with fiber-reinforced polymer tapes.

Cüneyt Aydin et al. developed a prognostic model for calculating the modulus of elasticity for normal dams and high-strength dams with the help of ANFIS [27]. Tesfamariam and Najjaran applied the ANFIS model to calculate the strength of concrete [28]. Ozgan et al. [29] developed an adaptive fuzzy neural system (ANFIS) Sugeno type for predicting stiffness parameters for asphalt concrete.

Chae and Abraham assessed the state of sewage pipelines using a fuzzy neural approach [30]. Adeli and Jiang [4] developed a fuzzy neutral model for calculating the capacity of work areas near highways. Nayak et al. modeled the connection and the interaction of soil and structures with the help of fuzzy neural networks. Nayak et al. [31] applied ANFIS to the hydrological modeling of river flows, that is, to the forecasting of time-varying data series.

Cao and Tian proposed the ANFIS model for predicting the need for industrial water [32]. Chen and Li made a model for the quality assessment of river water using the fuzzy neural network methodology [33]. F.-J. Chang and Y.-T. Chang applied a hybrid fuzzy neural approach for constructing a system for predicting the water level in reservoirs [34]. More precisely, they developed a prognostic ANFIS model for the management of accumulations, while the obtained results showed that it could successfully be applied to, precisely and credibly, predict the water level in reservoirs. Jianping et al. (2007) developed an improved model of fuzzy neural networks for analysis and deformation monitoring of dam shifts. Hamidian and Seyedpoor have used the methodology for fuzzy neural networks to determine the optimal shape of arch dams, as well as for predicting an effective response to the impact of earthquakes [35]. Thipparat and Thaseepetch applied the Sugeno type of ANFIS model so as to assess structure sustainability of highways in order to obtain relevant information about environmental protection [36].

An increased interest in the application of fuzzy neural networks to civil engineering can be seen in the last few decades. A comprehensive review of scientific papers which have elaborated on this issue published in scientific journals from 1995 until 2017 shows that fuzzy neural networks are mainly used to address several categories of problems: modeling and predicting, calculating and evaluating, and decision-making. The results of the conducted analysis illustrate the efficiency and practicality of applying this innovative technique towards the development of models for managing, decision-making, and assessing problems encountered when planning and implementing construction works. Their successful implementation represents a pillar for future research within the aforementioned categories, although the future application of fuzzy neural networks can be extended to other areas of civil engineering as well.

\section{Prognostic Modeling of the Fire Resistance of Eccentrically Loaded Reinforced Concrete Columns Using Fuzzy Neural Networks}

Eccentrically loaded columns are most commonly seen as the end columns in frame structures, and they are inserted in the partition walls that separate the structure from the surrounding environment or separating the fire compartment under fire conditions. The behavior of these types of columns, when exposed to fire, and the analysis of the influence of special 

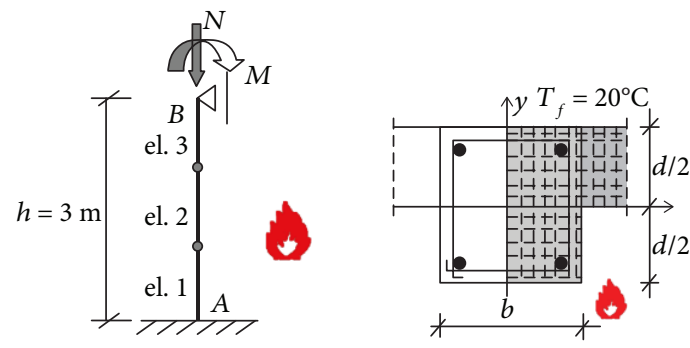

FIGURE 1: RC column inserted into the fire separation wall.

factors on their fire resistance have been analyzed in literature $[37,38]$.

Numerical analysis was carried out for the reinforced concrete column (Figure 1) exposed to standard fire ISO 834 [27]. Due to axial symmetry, only one-half of the cross section was analyzed $[37,38]$. The following input parameters were analyzed: the dimensions of the cross section, the intensity of initial load, the thickness of the protective concrete layer, the percentage of reinforcement, and the type of concrete (siliceous or carbonate). The output analysis result is the time period of fire resistance expressed in hours [37, 38].

The results from the numerical analysis [37] were used to create a prognostic model for determining the fire resistance of eccentrically loaded reinforced concrete columns in the fire compartment wall.

The application of fuzzy neural networks for the determination of fire resistance of eccentrically loaded reinforced concrete columns is presented below.

The prognostic model was developed using adaptive fuzzy neural networks-ANFIS in MathWorks software using an integrated Fuzzy Logic Toolbox module [39].

ANFIS represents an adaptive fuzzy neural inference system. The advantage of this technique is that membership functions of input parameters are automatically selected using a neuroadaptive training technique incorporated into the Fuzzy Logic Toolbox. This technique allows the fuzzy modeling process to learn from the data. This is how parameters of membership functions are calculated through which the fuzzy inference system best expresses input-output data groups [39].

ANFIS represents a fuzzy neural feedforward network consisting of neurons and direct links for connecting neurons. ANFIS models are generated with knowledge from data using algorithms typical of artificial neural networks. The process is presented using fuzzy rules. Essentially, neural networks are structured in several layers through which input data and fuzzy rules are generated. Similar to fuzzy logic, the final result depends on the given fuzzy rules and membership functions. The basic characteristic of ANFIS architecture is that part, or all, of the neurons is flexible, which means that their output depends on system parameters, and the training rules determine how these parameters are changed in order to minimize the prescribed error value [40].

ANFIS architecture consists of 5 layers and is illustrated in Figure 2 [3, 5-7, 40].
The first (input) layer of the fuzzy neural network serves to forward input data to the next layer $[3,5-7,40]$.

The second layer of the network (the first hidden layer) serves for the fuzzification of input variables. Each neuron within this layer is represented by the function: $O_{i}^{1}=\mu_{A i}(x)$, where $x$ denotes entrance into the neuron $i$ and $A_{i}$ denotes linguistic values. $O_{i}^{1}$ is in fact a membership function in $A_{i}$ indicating how many entrances $X_{i}$ satisfy a quantifier $A_{i}^{j}$. The parameters of this layer represent the parameters of the fuzzy rule premise [3, 5-7, 40].

The third layer (the second hidden layer) of the network consists of the $T$-norm operator for the calculation of fuzzy rule premise. Neurons are denoted as $\pi$, which represents a designation for the product of all input signals: $w_{i}=\mu_{A i}(x) \times \mu_{B i}(y)$. Each neuron from this layer establishes the rule strength of fuzzy rules $[3,5-7,40]$.

The fourth network layer (the third hidden layer) normalizes the rule strength. In each neuron, the relationship between the rule strength of the associated rule and the sum of all strengths is calculated: $\overline{w_{i}}=w_{i} / \sum w_{i}[3,5-7,40]$.

The procedure for determining subsequent parameters (conclusions) from fuzzy rules is carried out in the fifth layer (the fourth hidden layer). Each node from this layer is a square (adaptive) node marked by the function $O_{i}^{4}=\bar{w}_{i} Z_{i}=$ $\overline{w_{i}}\left(p_{i} X+q_{i} Y+r_{i}\right)$, where $\left\{p_{i}, q_{i}, r_{i}\right\}$ are conclusion parameters and $w_{i}$ is the output from the previous layer.

The output layer contains one neuron denoted by the letter $\Sigma$ due to the summing function. It calculates the total output as the sum of all input signals, in the function of premise parameters and fuzzy rule conclusions: $O_{i}^{5}=\sum \overline{w_{i}}$ $Z_{i}=\sum w_{i} Z_{i} / \sum w_{i}[3,5-7,40]$.

For a fuzzy neural network consisting of 2 input variables and 2 fuzzy rules (Figure 2), the total output would be calculated as follows $[3,5-7,40]$ :

$$
\begin{aligned}
Z= & \sum \overline{w_{i}} Z_{i}=\frac{\sum w_{i} Z_{i}}{\sum w_{i}}=\frac{w_{1}}{w_{1}+w_{2}} Z_{1}+\frac{w_{2}}{w_{1}+w_{2}} Z_{1} \\
= & \overline{w_{1}} Z_{1}+\overline{w_{2}} Z_{2}=\overline{w_{1}}\left(p_{1} X+q_{1} Y+r_{1}\right) \\
& +\bar{w}_{2}\left(p_{2} X+q_{2} Y+r_{2}\right),
\end{aligned}
$$

where $(X, Y)$ is the numerical input of the fuzzy neural network, $Z$ is the numerical output of the fuzzy neural network, $\left(\overline{w_{1}}, \overline{w_{2}}\right)$ are the normalized rule strengths of fuzzy rules expressed through the fuzzy rule premise, and $\left(p_{1}, q_{1}, r_{1}\right.$, $\left.p_{2}, q_{2}, r_{2}\right)$ are the parameters of the fuzzy rule conclusions.

The ANFIS training algorithm consists of two segments: reverse propagation method (backpropagation algorithm), which determines errors of variables from a recursive path, from the output to the input layers, determining variable errors, that is, parameters of the membership function, and the least square method determining the optimal set of consequent parameters. Each step in the training procedure consists of two parts. In the first part, input data is propagated and optimal consequent parameters are estimated using the iterative least-mean-square method, while fuzzy rule premise parameters are assumed to be fixed for the current cycle through the training set. In the second part, input data is propagated again, but in this process, the 


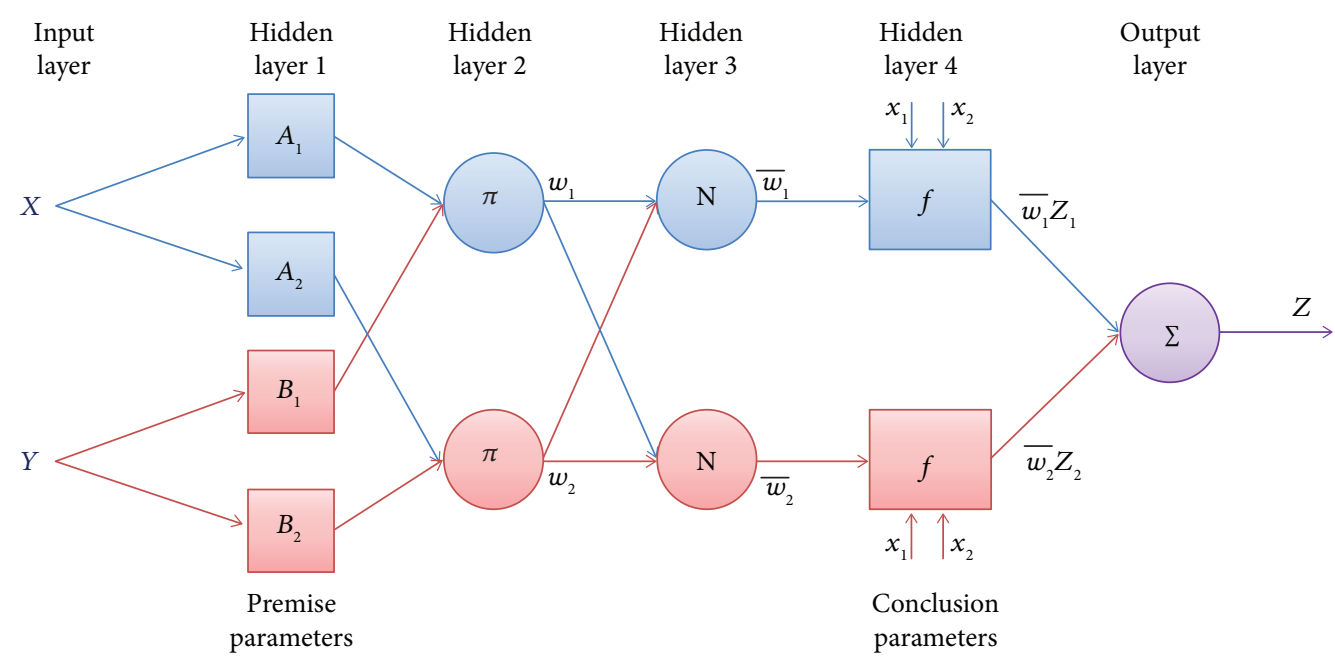

FIgURE 2: An overview of the ANFIS network.

backpropagation algorithm is used to modify the premise parameter while the consequent parameters remain fixed. This procedure is iterated $[3,5-7,40]$.

For the successful application of ANFIS during the process of solving a specific problem task, it is necessary to possess solid professional knowledge of the problem at hand and appropriate experience. This enables a correct and accurate choice of input variables, that is, unnecessarily complicating the model by adding nonsignificant variables, or not including important parameters that have a significant effect on output values, is avoided.

The application of fuzzy neural network techniques to the modeling process is carried out in a few steps [39, 41]: assembling and processing data, determining the parameters and structure of the fuzzy neural network (creating the fuzzy inference system), training the fuzzy neural network, and testing the fuzzy neural network and prognostics.

For the purpose of prognostic modeling of the eccentrically loaded RC columns, the structure of the fuzzy neural network consists of 6 input variables (dimensions of the reinforced concrete column ( $b$ and $d$ ), thickness of the protective concrete layer $(a)$, percentage of reinforcement $(\mu)$, axial load coefficient $(\eta)$, bending moment coefficient $(\beta)$, and one output variable (fire resistance of the reinforced concrete column $(t))$.

One of the most crucial aspects, when using a fuzzy neural networks as prognostic modeling technique, is to collect accurate and appropriate data sets. The data has to contain a finite number of sets where each data set has to be defined with an exact input and output values. Another very important aspect is to have large amount of data sets. Data sets are divided into two main groups: data used for training of the model and data used for testing of the model prediction accuracy. The training data should contain all the necessary representative features, so the process of selecting a data set for checking or testing purposes is made easier. One problem for models constructed using adaptive techniques is selecting a data set that is both representative of the data the trained model is intended to imitate, yet sufficiently distinct from the training data set so as not to render the validation process trivial. To design an ANFIS system for real-world problems, it is essential to select the parameters for the training process. It is essential to have proper training and testing data sets. If the data sets are not selected properly, then the testing data set will not validate the model. If the testing data set is completely different from the training data set, then the model cannot capture any of the features of the testing data. Then, the minimum testing error can be achieved in the first epoch. For the proper data set, the testing error decreases with the training proceeding until a jump point. The selection of data sets for training and testing of the ANFIS system is an important factor affecting the performance of the model. If the data sets used for testing is extremely different from one of the training data sets, then the system fails to capture the essential features of the data set. Another aspect that has to be emphasized is that all data sets have to be properly selected, adequately collected, and exact. The basic characteristic of all computer programs used for calculation and modeling applies for the neural networks as well: only quality input can give a quality output! Even though neural networks represent an intelligent modeling technique, they are not omnipotent, which means that if the input data sets are not clear and correct, the neural network model will not be able to produce accurate output results.

A training data group is used to initially create a model structure [39]. The training process is a learning process of the developed model. The model is trained till the results are obtained with minimum error. During the learning process, the parameters of the membership functions are updated. In MATLAB, the two ANFIS parameter optimization methods are hybrid (combination of least squares and back propagation method) and back propagation. Error tolerance is used as training stopping criterion, which is related to the error size. The training will stop after the training data error remains within this tolerance. The training error is the difference between the training data output value and the output of the fuzzy inference system corresponding to the same training data input value (the one associated with that training data output value). 


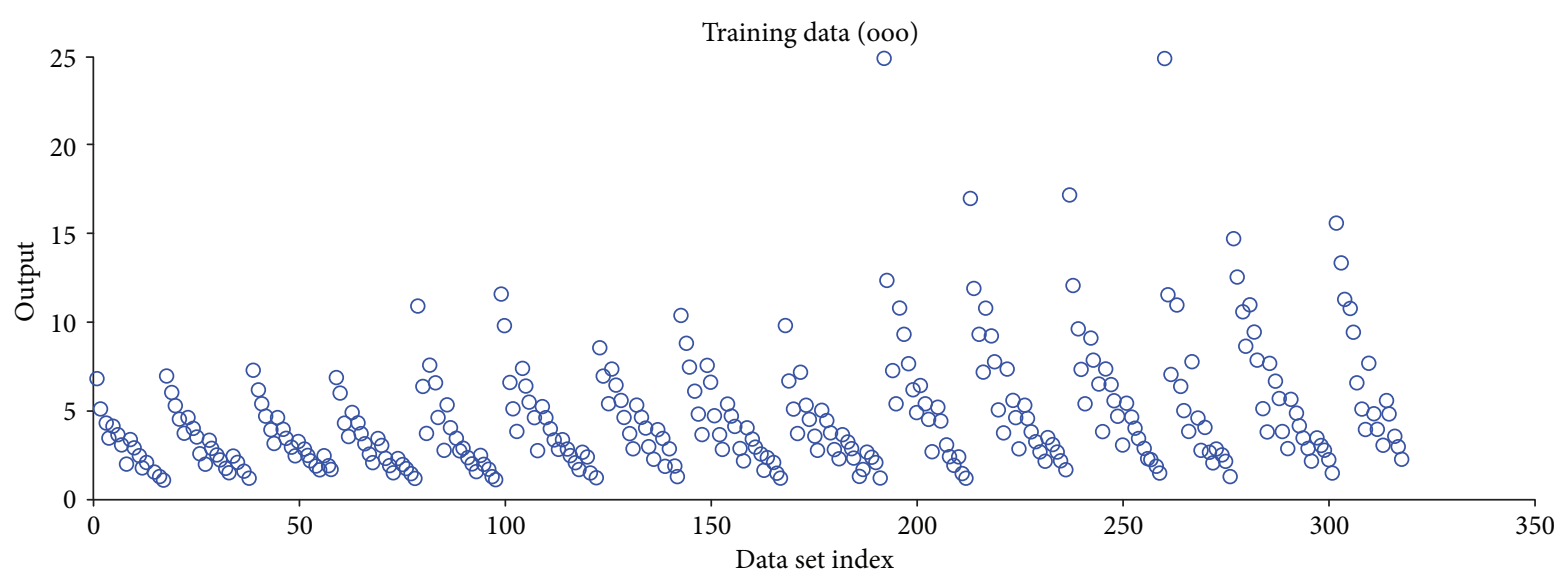

Figure 3: Graphical representation of the training data loaded into ANFIS.

The data groups used for checking and testing of the model are also referred as validation data and are used to check the capabilities of the generalization model during training [39]. Model validation is the process by which the input data sets on which the FIS was not trained are presented to the trained FIS model, to see the performance. The validation process for the ANFIS model is carried out by leaking vectors from the input-output testing data into the model (data not belonging to the training group) in order to verify the accuracy of the predicted output. Testing data is used to validate the model. The testing data set is used for checking the generalization capability of the ANFIS model. However, it is desirable to extract another group of inputoutput data, that is, checking data, in order to avoid the possibility of an "overfitting." The idea behind using the checking data stems from the fact that a fuzzy neural network may, after a certain number of training cycles, be "overtrained," meaning that the model practically copies the output data instead of anticipating it, providing great predictions but only for training data. At that point, the prediction error for checking data begins to increase when it should exhibit a downward trend. A trained network is tested with checking data, and parameters for membership functions are chosen for which minimal errors are obtained. These data controls this phenomenon by adjusting ANFIS parameters, with the aim of achieving the least errors in prediction. However, when selecting data for model validation, a detailed database study is required because the validation data should be not only sufficiently representative of the training data but also sufficiently different to avoid marginalization of training $[39,41]$.

Even though there are many published researches worldwide that investigate the impact of the proportion of data used in various subsets on neural network model, there is no clear relationship between the proportion of data for training, testing and validation, and model performance. However, many authors recommend that the best result can be obtained when $20 \%$ of the data are used for validation and the remaining data are divided into $70 \%$ for training and $30 \%$ for testing. The number of training and testing data sets greatly depends on the total number of data sets. So, the real apportion of train and test data set is closely related with the real situation, problem specifics, and the quantity of the data set. There are no strict rules regarding the data set division, so when using the adaptive modeling techniques, it is very important to know how well the data sets describe the features of the problem and to have a decent amount of experience and knowledge about neural networks [42, 43].

The database used for ANFIS modeling, for the model presented in this paper, expressed through input and output variables, was obtained from a numerical analysis. A total of 398 input-output data series were analyzed, out of which 318 series ( $80 \%)$ were used for network training, and 80 series (20\%) were data for testing the model. The prediction of the output result was performed on new 27 data sets. The three data groups loaded into ANFIS are presented in Figures 3-5.

For a precise and reliable prediction of fire resistance for eccentrically loaded reinforced concrete columns, different ANFIS models were analyzed with the application of the subtractive clustering method and a hybrid training mode.

The process of training fuzzy neural networks involves adjusting the parameters of membership functions. Training is an iterative process that is carried out on training data sets for fuzzy neural networks [39]. The training process ends when one of the two defined criteria has been satisfied; these are error tolerance percentage and number of iterations. For the analysis in this research, the values of these criteria were 0 for error tolerance and 100 for number of training iterations.

After a completed training process of the generated ANFIS model, it is necessary to validate the model using data sets defined for testing and checking [39, 44]: the trained model is tested using validation data, and the obtained average errors and the estimated output values are analyzed.

The final phase of the modeling using fuzzy neural networks is prognosis of outputs and checking the model's prediction accuracy. To this end, input data is passed through the network to generate output results [39,44]. If low values of average errors have been obtained during the testing and validation process of the fuzzy neural network, then it is quite certain that a trained and validated ANFIS model can be applied for a high-quality and precise prognosis of output values.

For the analyzed case presented in this paper, the optimal ANFIS model is determined by analyzing various fuzzy 


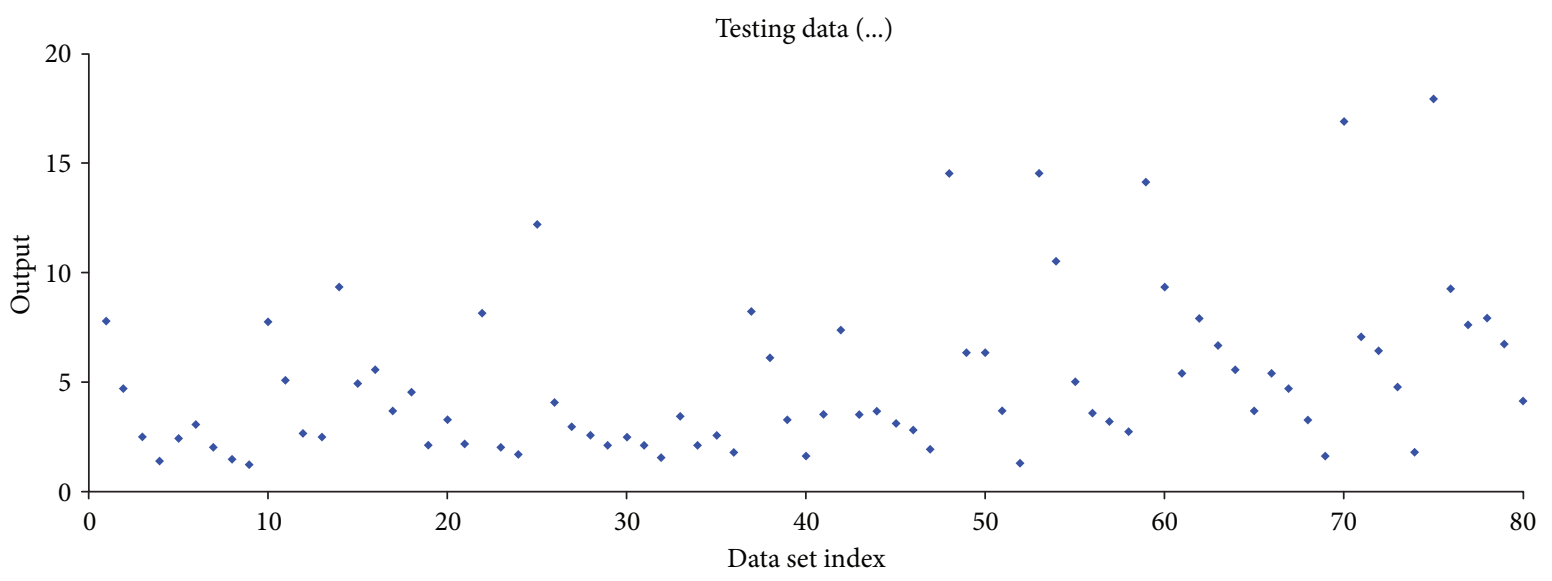

FIgURE 4: Graphical representation of the test data loaded into ANFIS.

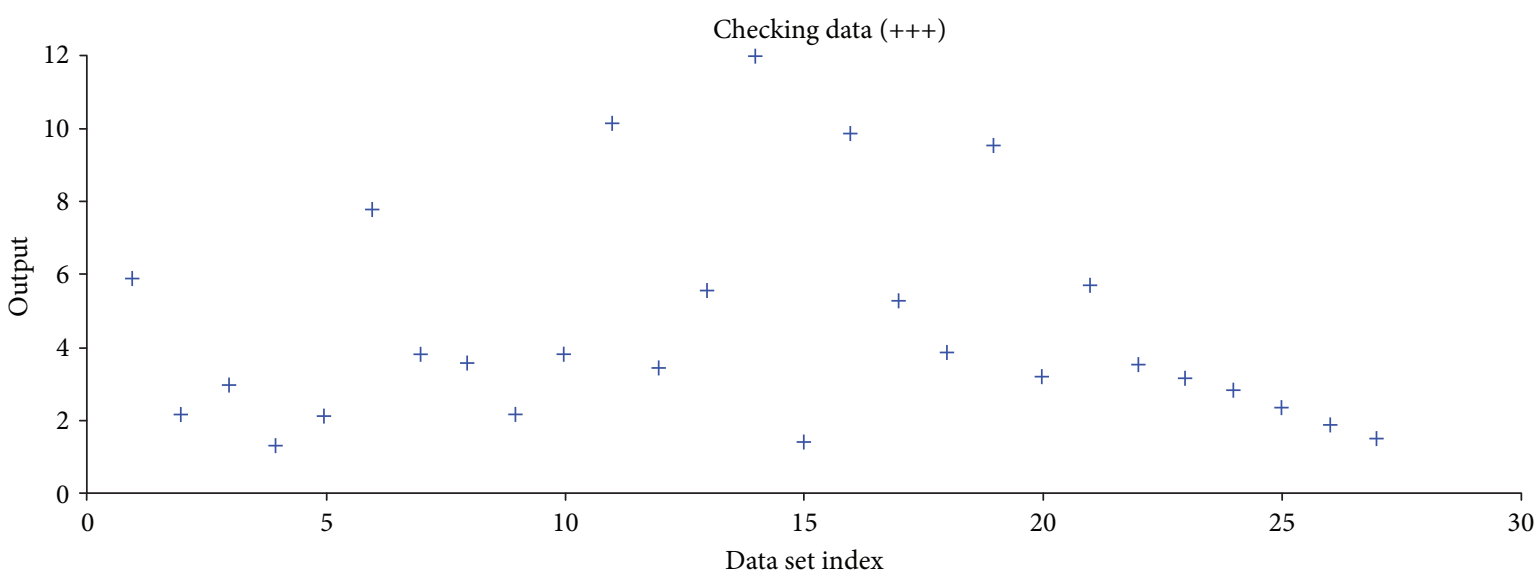

FIGURE 5: Graphical representation of the checking data loaded into ANFIS.

neural network architectures obtained by varying the following parameters: the radius of influence (with values from 0.6 to 1.8 ) and the compaction factor (with values in the interval from 0.45 to 2.5). The mutual acceptance ratio and the mutual rejection ratio had fixed values based on standard values defined in MATLAB, amounting to 0.5 and 0.15 [39]. A specific model of the fuzzy neural network, with a designation depending on the parameter values, was created for each combination of these parameters. The optimal combination of parameters was determined by analyzing the behavior of prognostic models and by comparing obtained values for average errors during testing and predicting output values. Through an analysis of the results, it can be concluded that the smallest value for average error in predicting fire resistance of eccentrically loaded reinforced concrete columns is obtained using the FIS11110 model with Gaussian membership function (gaussMF) for the input variable and linear output function, with 8 fuzzy rules. The average error during model testing was 0.319 for training data, 0.511 for testing data, and 0.245 for verification data.

Figure 6 gives a graphical representation of the architecture of the adopted ANFIS model, composed of 6 input

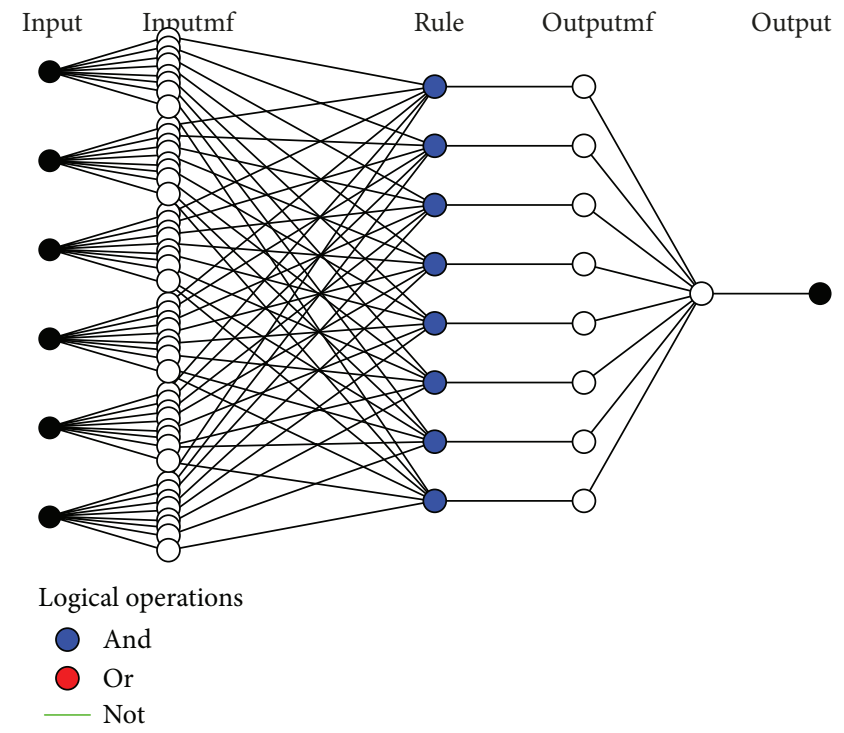

FIgURE 6: Architecture of ANFIS model FIS11110 composed of 6 input variables and 1 output variable. 


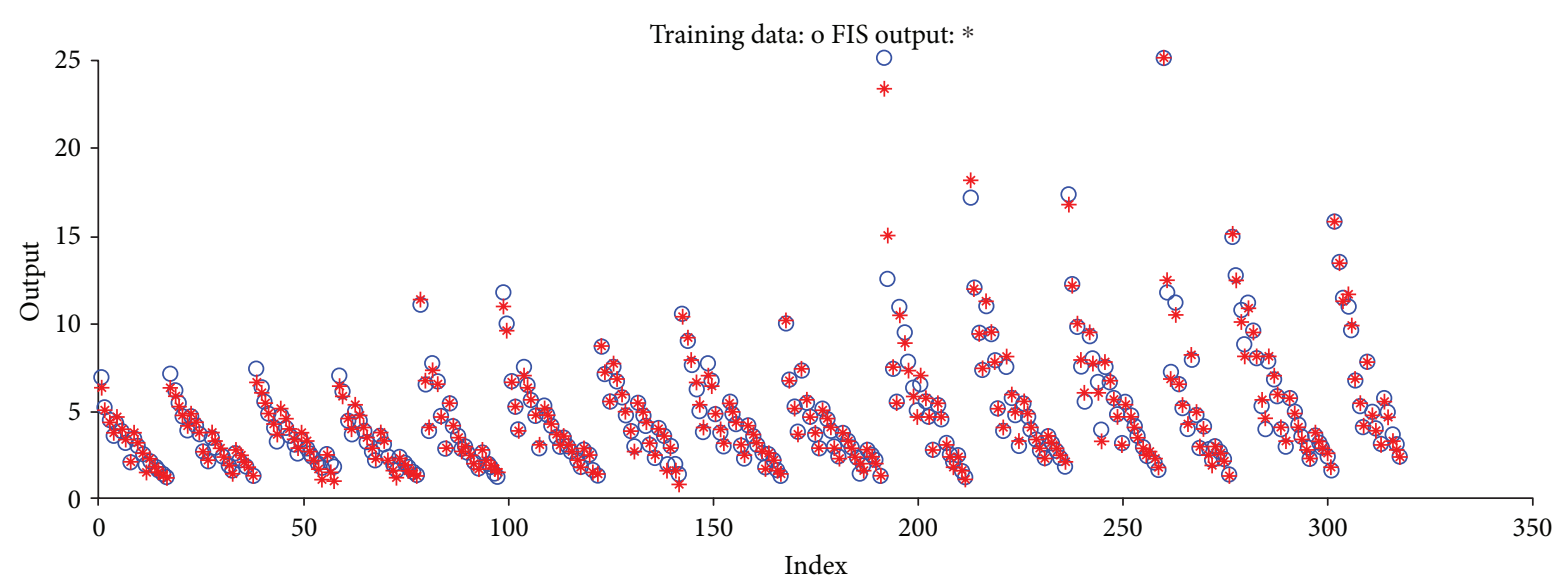

FIGURE 7: Comparison of the actual and predicted values of fire resistance time for RC columns obtained with ANFIS training data.

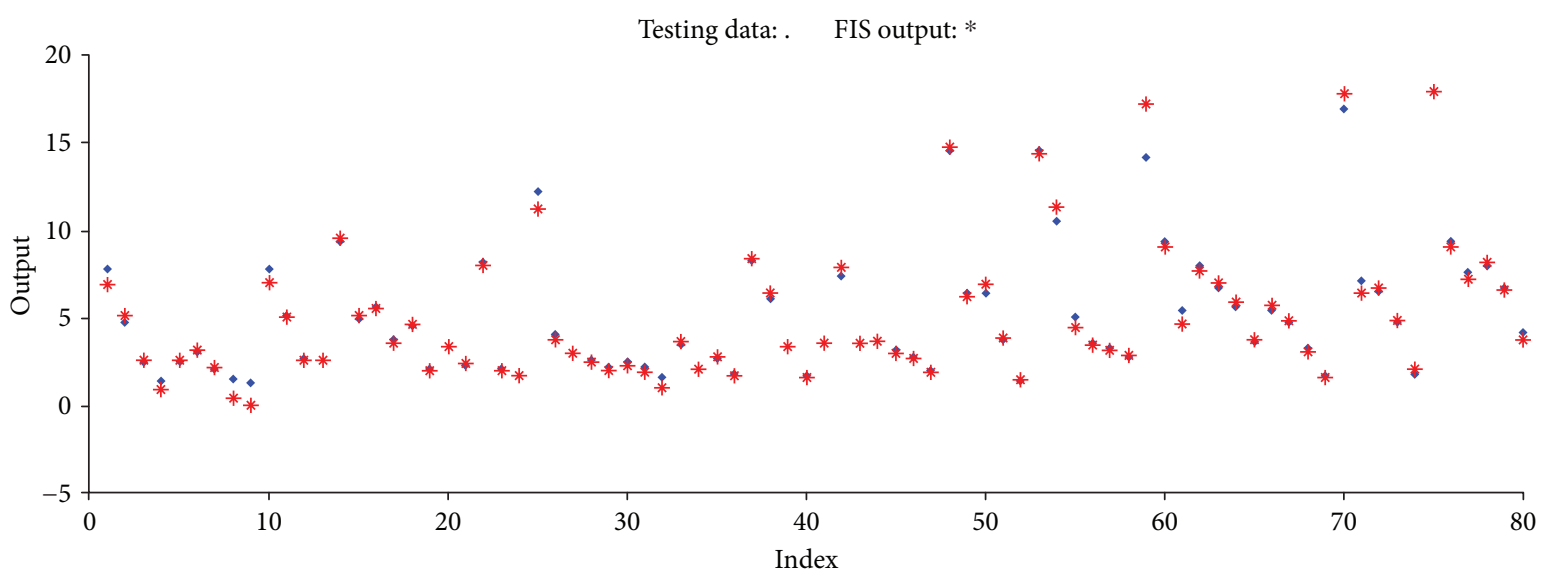

FIgURE 8: A comparison of actual and predicted values of fire resistance time for RC columns obtained from the ANFIS testing data.

variables defined by Gaussian membership functions and 1 output variable.

The training of the ANFIS model was carried out with 318 input-output data groups. A graphic representation of fire resistance for the analyzed reinforced concrete columns obtained by numerical analysis [37] and the predicted values obtained by the FIS11110 prognostic model for the training data is given in Figure 7.

It can be concluded that the trained ANFIS prognostic model provides excellent results and quite accurately predicts the time of fire resistance of the analyzed reinforced concrete, for input data that belong to the size intervals the network was trained for - the analyzed 318 training cases. The average error that occurs when testing the network using training data is 0.319 .

The testing of the ANFIS model was carried out using 80 input/output data sets. A graphical comparison representation of the actual and predicted values of fire resistance for analyzed reinforced concrete columns, for the testing data sets, is presented in Figure 8.

Figures 7 and 8 show an excellent match between predicted values obtained from the ANFIS model with the actual values obtained by numerical analysis [37]. The average error that occurs when testing the fuzzy neural network using testing data is 0.511 .

Figure 9 presents the fuzzy rules, as part of the Fuzzy Logic Toolbox program, of the trained ANFIS model FIS11110. Each line in the figure corresponds to one fuzzy rule, and the input and output variables are subordinated in the columns. Entering new values for input variables automatically generates output values, which very simply predicts fire resistance for the analyzed reinforced concrete columns.

The precision of the ANFIS model was verified using 27 input-output data groups (checking data), which also represents a prognosis of the fuzzy neural network because they were not used during the network training and testing. The obtained predicted values for fire resistance for the analyzed reinforced concrete columns are presented in Table 1. A graphic representation of the comparison between actual values (obtained by numerical analysis [37]) and predicted values (obtained through the ANFIS model FIS11110) for fire resistance of eccentrically loaded reinforced concrete columns in the fire compartment wall is presented in Figure 10.

An analysis of the value of fire resistance for the analyzed eccentrically loaded reinforced concrete columns shows that the prognostic model made with fuzzy neural networks 


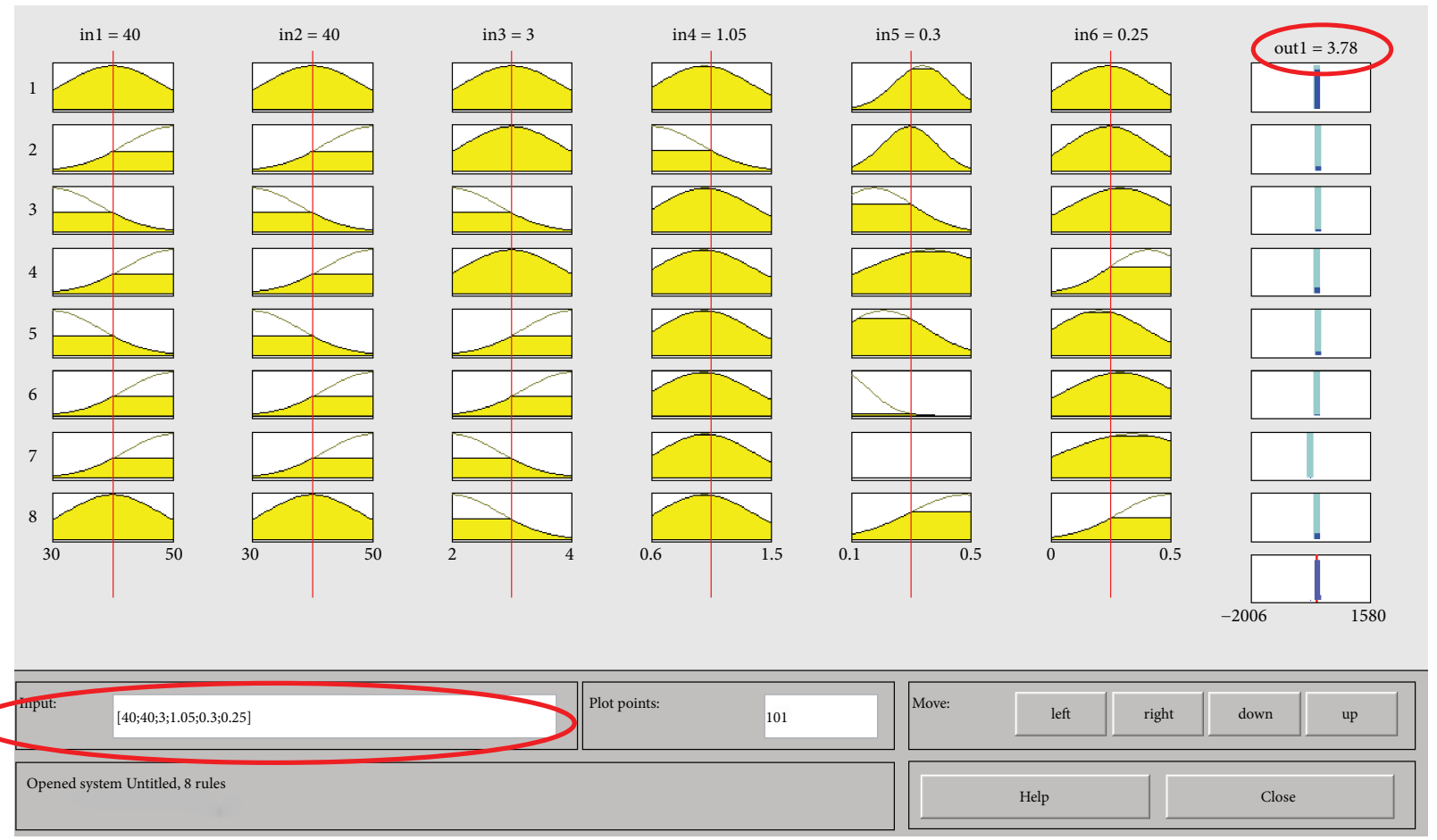

FIGURE 9: Illustration of fuzzy rules for the ANFIS model FIS11110.

provides a precise and accurate prediction of output results. The average square error obtained when predicting output results using a fuzzy neural network (ANFIS) is 0.242 .

This research indicates that this prognostic model enables easy and simple determination of fire resistance of eccentrically loaded reinforced concrete columns in the fire compartment wall, with any dimensions and characteristics.

Based on a comparison of results obtained from a numerical analysis and results obtained from the prognostic model made from fuzzy neural networks, it can be concluded that fuzzy neural networks represent an excellent tool for determining (predicting) fire resistance of analyzed columns. The prognostic model is particularly useful when analyzing columns for which there is no (or insufficient) previous experimental and/or numerically derived data, and a quick estimate of its fire resistance is needed. A trained fuzzy neural network gives high-quality and precise results for the input data not included in the training process, which means that a projected prognostic model can be used to estimate reinforced concrete columns of any dimension and characteristic (in case of centric load). It is precisely this positive fact that fully justifies the implementation of more detailed and extensive research into the application of fuzzy neural networks for the design of prognostic models that could be used to estimate different parameters in the construction industry.

\section{Conclusion}

Prognostic models based on the connection between popular methods for soft computing, such as fuzzy neural networks, use positive characteristics of neural networks and fuzzy systems. Unlike traditional prognostic models that work precisely, definitely, and clearly, fuzzy neural models are capable of using tolerance for inaccuracy, uncertainty, and ambiguity. The success of the ANFIS is given by aspects like the designated distributive inferences stored in the rule base, the effective learning algorithm for adapting the system's parameters, or by the own learning ability to fit an irregular or nonperiodic time series. The ANFIS is a technique that embeds the fuzzy inference system into the framework of adaptive networks. The ANFIS thus draws the benefits of both ANN and fuzzy techniques in a single framework. One of the major advantages of the ANFIS method over fuzzy systems is that it eliminates the basic problem of defining the membership function parameters and obtaining a set of fuzzy if-then rules. The learning capability of ANN is used for automatic fuzzy if-then rule generation and parameter optimization in the ANFIS. The primary advantages of the ANFIS are the nonlinearity and structured knowledge representation. Research and applications on fuzzy neural networks made clear that neural and fuzzy hybrid systems are beneficial in fields such as the applicability of existing algorithms for artificial neural networks (ANNs), and direct adaptation of knowledge articulated as a set of fuzzy linguistic rules. A hybrid intelligent system is one of the best solutions in data modeling, where it is capable of reasoning and learning in an uncertain and imprecise environment. It is a combination of two or more intelligent technologies. This combination is done usually to overcome single intelligent technologies. Since ANFIS combines the advantages of both neural network and fuzzy logic, it is capable of handling complex and nonlinear problems.

The application of fuzzy neural networks, as an unconventional approach, for prediction of the fire resistance of 
TABLE 1: Actual and predicted value of fire resistance time for RC columns obtained with the ANFIS checking data.

\begin{tabular}{|c|c|c|c|c|c|c|c|}
\hline & & & & Checking & & & \\
\hline Colun & ins & Thickness of the & Percentage of & Axial load & Bending moment & $\begin{array}{r}\text { Fire resista } \\
\text { loa }\end{array}$ & $\begin{array}{l}\text { ce time of eccentrically } \\
\text { led RC columns }\end{array}$ \\
\hline & & & & & & Actual values & Predicted values (ANFIS) \\
\hline$b$ & $d$ & $a$ & $\mu$ & $\eta$ & $\beta$ & $t$ & $t$ \\
\hline 30.00 & 30.00 & 2.00 & 1.00 & 0.10 & 0.2 & 5.88 & 5.53 \\
\hline 30.00 & 30.00 & 2.00 & 1.00 & 0.30 & 0.3 & 2.14 & 1.87 \\
\hline 30.00 & 30.00 & 3.00 & 1.00 & 0.10 & 0.5 & 2.94 & 3.44 \\
\hline 30.00 & 30.00 & 3.00 & 1.00 & 0.40 & 0.4 & 1.32 & 1.32 \\
\hline 30.00 & 30.00 & 4.00 & 1.00 & 0.40 & 0.1 & 2.08 & 1.83 \\
\hline 40.00 & 40.00 & 2.00 & 1.00 & 0.10 & 0.2 & 7.76 & 7.98 \\
\hline 40.00 & 40.00 & 2.00 & 1.00 & 0.40 & 0 & 3.82 & 3.83 \\
\hline 40.00 & 40.00 & 3.00 & 1.00 & 0.20 & 0.4 & 3.56 & 3.74 \\
\hline 40.00 & 40.00 & 3.00 & 1.00 & 0.30 & 0.5 & 2.16 & 2.28 \\
\hline 40.00 & 40.00 & 3.00 & 1.00 & 0.40 & 0 & 3.8 & 3.77 \\
\hline 40.00 & 40.00 & 4.00 & 1.00 & 0.10 & 0.1 & 10.14 & 9.9 \\
\hline 40.00 & 40.00 & 4.00 & 1.00 & 0.30 & 0.3 & 3.44 & 3.61 \\
\hline 40.00 & 40.00 & 3.00 & 0.60 & 0.20 & 0.2 & 5.56 & 5.52 \\
\hline 40.00 & 40.00 & 3.00 & 1.50 & 0.10 & 0 & 12 & 11.7 \\
\hline 40.00 & 40.00 & 3.00 & 1.50 & 0.50 & 0.4 & 1.38 & 1.28 \\
\hline 50.00 & 50.00 & 2.00 & 1.00 & 0.10 & 0.3 & 9.83 & 10.1 \\
\hline 50.00 & 50.00 & 3.00 & 1.00 & 0.10 & 0.5 & 5.28 & 5.59 \\
\hline 50.00 & 50.00 & 4.00 & 1.00 & 0.30 & 0.4 & 3.84 & 3.61 \\
\hline 50.00 & 50.00 & 2.00 & 0.60 & 0.20 & 0.1 & 9.5 & 9.03 \\
\hline 50.00 & 50.00 & 2.00 & 0.60 & 0.50 & 0 & 3.18 & 3.37 \\
\hline 50.00 & 50.00 & 4.00 & 0.60 & 0.30 & 0.2 & 5.7 & 5.53 \\
\hline 50.00 & 50.00 & 4.00 & 0.60 & 0.50 & 0 & 3.52 & 3.53 \\
\hline 50.00 & 50.00 & 4.00 & 0.60 & 0.50 & 0.1 & 3.14 & 3.13 \\
\hline 50.00 & 50.00 & 4.00 & 0.60 & 0.50 & 0.2 & 2.8 & 2.81 \\
\hline 50.00 & 50.00 & 4.00 & 0.60 & 0.50 & 0.3 & 2.32 & 2.52 \\
\hline 50.00 & 50.00 & 4.00 & 0.60 & 0.50 & 0.4 & 1.88 & 2.2 \\
\hline 50.00 & 50.00 & 4.00 & 0.60 & 0.50 & 0.5 & 1.48 & 1.86 \\
\hline
\end{tabular}

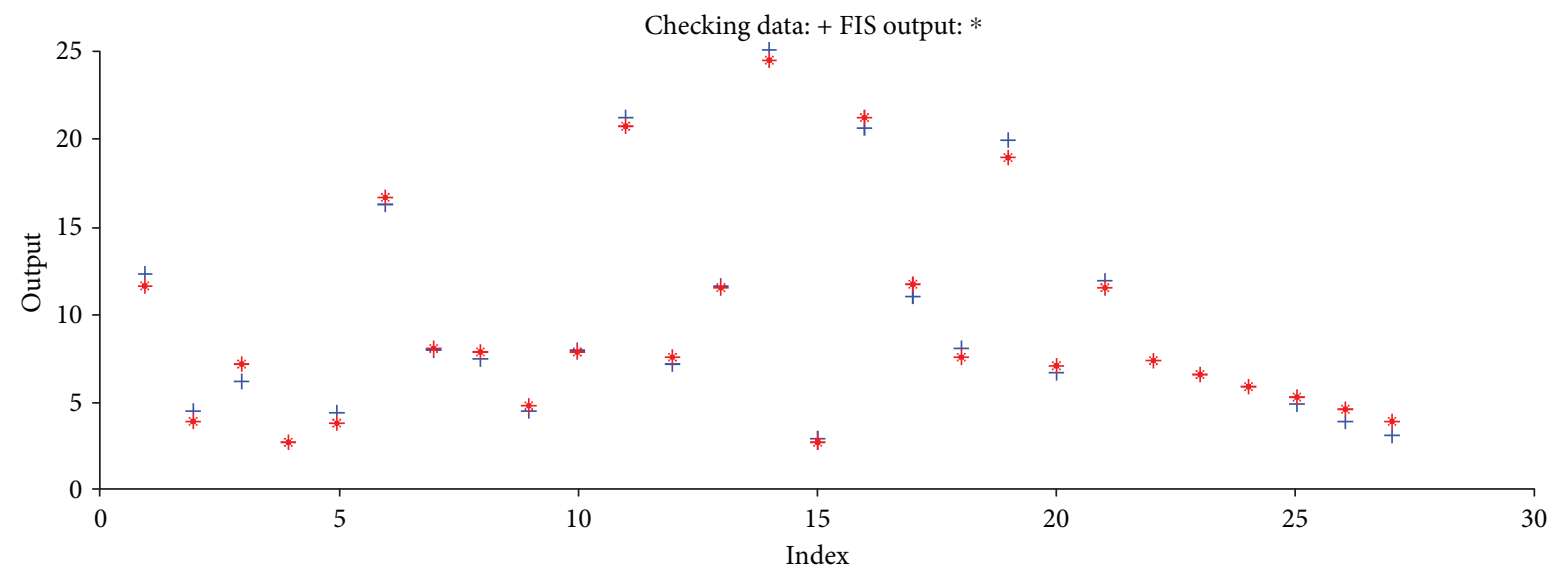

FIGURE 10: Comparison of actual and predicted values of fire resistance time of RC columns obtained using the ANFIS checking data. 
structural elements has a huge significance in the modernization of the construction design processes. Most of the experimental models for the determination of fire resistance are extremely expensive, and analytical models are quite complicated and time-consuming. That is why a modern type of analyses, such as modeling through fuzzy neural networks, can help, especially in those cases where some prior analyses were already made.

This paper presents some of the positive aspects of their application for the determination the fire resistance of eccentrically loaded RC columns exposed to standard fire from one side. The influence of the cross-sectional dimensions, thickness of the protective concrete layer, percentage of reinforcement, and the intensity of the applied loads to the fire resistance of eccentrically loaded RC columns were analyzed using the program FIRE. The results of the performed numerical analyses were used as input parameters for training of the ANFIS model. The obtained outputs demonstrate that the ANFIS model is capable of predicting the fire resistance of the analyzed RC columns.

The results from this research are proof of the successful application of fuzzy neural networks for easily and simply solving actual complex problems in the field of construction. The obtained results, as well as the aforementioned concluding considerations, emphasize the efficiency and practicality of applying this innovative technique for the development of management models, decision making, and assessment of problems encountered during the planning and implementation of construction projects/works.

A fundamental approach based on the application of fuzzy neural networks enables advanced and successful modeling of fire resistance of reinforced concrete columns embedded in the fire compartment wall, exposed to fire on one side, thus overcoming defects typical for traditional methods of mathematical modeling.

\section{Data Availability}

The data used to support the findings of this study are available from the corresponding author upon request.

\section{Conflicts of Interest}

The authors declare that they have no conflicts of interest.

\section{References}

[1] EN1994-1-2, Eurocode 4 - Design of Composite Steel and Concrete Structures, Part 1-2: General Rules - Structural Fire Design, European Committee for Standardization, Management Centre, 2005.

[2] A. Abraham and B. Nath, "A neuro-fuzzy approach for modelling electricity demand in Victoria," Applied Soft Computing, vol. 1, no. 2, pp. 127-138, 2001.

[3] A. Abrahim, "Neuro fuzzy systems: state-of-the-art modeling techniques," in Connectionist Models of Neurons, Learning Processes and Artificial Intelligence, Lecture notes in Computer sciences, J. Mira and A. Prieto, Eds., pp. 269-276, SpringerVerlag, Germany, 2001.
[4] H. Adeli and X. Jiang, "Neuro-fuzzy logic model for freeway work zone capacity estimation," Journal of Transportation Engineering, vol. 129, no. 5, pp. 484-493, 2003.

[5] A. Abraham, It Is Time to Fuzzify Neural Networks! (Tutorial), International Conference on Intelligent Multimedia and Distance Education, Fargo, USA, 2001.

[6] D. Fuller, Neural Fuzzy Systems, Abo Akademi University, 1995.

[7] M. F. Azeem, Ed., Fuzzy Inference System-Theory and Applications, InTechOpen, 2012.

[8] N. K. Kasabov, "Foundations of neural networks, fuzzy systems and knowledge engineering," in A Bradford Book, The MIT Press, Cambridge, London, England, 1998.

[9] A. Abrahim and M. R. Khan, "Neuro-fuzzy paradigms for intelligent energy management," in Connectionist Models of Neurons, Learning Processes and Artificial Intelligence, Lecture notes in Computer sciences, J. Mira and A. Prieto, Eds., Springer-Verlag Berlin Heidelberg, 2004.

[10] A. H. Boussabaine and T. M. S. Elhag, A Neurofuzzy Model for Predicting Cost and Duration of Construction Projects, Royal Institution of Chartered Surveyors, 1997.

[11] S. S. H. Yasrebi and M. Emami, "Application of artificial neural networks (ANNs) in prediction and interpretation of Pressuremeter test results," in The 12th International Conference of International Association for Computer Methods and Advances in Geomechanics (IACMAG), pp. 1634-1638, India, 2008.

[12] K. C. Lam, T. Hu, S. Thomas Ng, M. Skitmore, and S. O. Cheung, "A fuzzy neural network approach for contractor prequalification," Construction Management and Economics, vol. 19, no. 2, pp. 175-188, 2001.

[13] C. H. Ko and M. Y. Cheng, "Hybrid use of AI techniques in developing construction management tools," Automation in Construction, vol. 12, no. 3, pp. 271-281, 2003.

[14] J. Jassbi and S. Khanmohammadi, Organizational Risk Assessment Using Adaptive Neuro-Fuzzy Inference System, IFSA-EUSFLAT, 2009.

[15] M.-Y. Cheng, H.-C. Tsai, C.-H. Ko, and W.-T. Chang, "Evolutionary fuzzy neural inference system for decision making in geotechnical engineering," Journal of Computing in Civil Engineering, vol. 22, no. 4, pp. 272-280, 2008.

[16] A. Rashidi, F. Jazebi, and I. Brilakis, "Neurofuzzy genetic system for selection of construction project managers," Journal of Construction Engineering and Management, vol. 137, no. 1, pp. 17-29, 2011.

[17] E. Mehdi and G. Reza, "Risk assessment of construction projects using network based adaptive fuzzy system," International Journal of Academic Research, vol. 3, no. 1, p. 411, 2011.

[18] W. F. Feng and W. J. Zhu, "The application of SOFM fuzzy neural network in project cost estimate," Journal of Software, vol. 6, no. 8, pp. 1452-1459, 2011.

[19] M. R. Feylizadeh, A. Hendalianpour, and M. Bagherpour, "A fuzzy neural network to estimate at completion costs of construction projects," International Journal of Industrial Engineering Computations, vol. 3, no. 3, pp. 477484, 2012.

[20] S. A. Ramu and V. T. Johnson, "Damage assessment of composite structures-a fuzzy logic integrated neural network approach," Computers \& Structures, vol. 57, no. 3, pp. 491502, 1995. 
[21] M. Y. Liu and Y. Wei-guo, "Research on safety assessment of long-span concrete-filled steel tube arch bridge based on fuzzy-neural network," China Journal of Highway and Transport, vol. 4, p. 012, 2004.

[22] E. T. Foncesa, A Neuro-Fuzzy System for Steel Beams Patch Load Prediction, Fifth International Conference on Hybrid Intelligent Systems, 2005.

[23] B. Wang, X. Liu, and C. Luo, Research on the Safety Assessment of Bridges Based on Fuzzy-Neural Network, Proceedings of the Second International Symposium on Networking and Network Security, China, 2010.

[24] M. Jakubek, "Fuzzy weight neural network in the analysis of concrete specimens and R/C column buckling tests," Computer Assisted Methods in Engineering and Science, vol. 18, no. 4, pp. 243-254, 2017.

[25] A. Tarighat, "Fuzzy inference system as a tool for management of concrete bridges," in Fuzzy Inference System-Theory and Applications, M. F. Azeem, Ed., IntechOpen, 2012.

[26] M. A. Mashrei, "Neural network and adaptive neuro-fuzzy inference system applied to civil engineering problems," in Fuzzy Inference System-Theory and Applications, IntechOpen, 2012.

[27] A. Cüneyt Aydin, A. Tortum, and M. Yavuz, "Prediction of concrete elastic modulus using adaptive neuro-fuzzy inference system," Civil Engineering and Environmental Systems, vol. 23, no. 4, pp. 295-309, 2006.

[28] S. Tesfamariam and H. Najjaran, "Adaptive network-fuzzy inferencing to estimate concrete strength using mix design," Journal of Materials in Civil Engineering, vol. 19, no. 7, pp. 550-560, 2007.

[29] E. Özgan, İ. Korkmaz, and M. Emiroğlu, “Adaptive neurofuzzy inference approach for prediction the stiffness modulus on asphalt concrete," Advances in Engineering Software, vol. 45, no. 1, pp. 100-104, 2012.

[30] M. J. Chae and D. M. Abraham, "Neuro-fuzzy approaches for sanitary sewer pipeline condition assessment," Journal of Computing in Civil Engineering, vol. 15, no. 1, pp. 4-14, 2001.

[31] P. C. Nayak, K. P. Sudheer, D. M. Rangan, and K. S. Ramasastri, "A neuro-fuzzy computing technique for modeling hydrological time series," Journal of Hydrology, vol. 291, no. 1-2, pp. 52-66, 2004.

[32] A. Cao and L. Tian, "Application of the adaptive fuzzy neural network to industrial water consumption prediction," Journal of Anhui University of Technology and Science, vol. 3, 2005.

[33] S. Y. Chen and Y. W. Li, "Water quality evaluation based on fuzzy artificial neural network," Advances in Water Science, vol. 16, no. 1, pp. 88-91, 2005.

[34] F.-J. Chang and Y.-T. Chang, "Adaptive neuro-fuzzy inference system for prediction of water level in reservoir," Advances in Water Resources, vol. 29, no. 1, pp. 1-10, 2006.

[35] D. Hamidian and S. M. Seyedpoor, "Shape optimal design of arch dams using an adaptive neuro-fuzzy inference system and improved particle swarm optimization," Applied Mathematical Modelling, vol. 34, no. 6, pp. 1574-1585, 2010.

[36] T. Thipparat and T. Thaseepetch, "Application of neuro-fuzzy system to evaluate sustainability in highway desigh," International Journal of Modern Engineering Research, vol. 2, no. 5, pp. 4153-4158, 2012.

[37] M. Cvetkovska, Nonlinear Stress Strain Behavior of $R C$ Elements and Plane Frame Structures Exposed to Fire, Doctoral
Dissertation, Civil Engineering Faculty in Skopje, "Sts Cyril and Methodius" University, Macedonia, 2002.

[38] M. Lazarevska, M. Knežević, M. Cvetkovska, N. Ivanišević, T. Samardzioska, and A. T. Gavriloska, "Fire-resistance prognostic model for reinforced concrete columns," Gradevinar, vol. 64, p. 7, 2012.

[39] http://www.mathworks.com/products/fuzzy-logic/.

[40] J.-S. R. Jang, “ANFIS: adaptive-network-based fuzzy inference system," IEEE Transactions on Systems, Man, and Cybernetics, vol. 23, no. 3, pp. 665-685, 1993.

[41] J. Guan, J. Zurada, and S. Levitian, “An adaptive neuro-fuzzy inference system based approach to real estate property assessment," Journal of Real Estate Research, vol. 30, no. 4, pp. 395-421, 2008.

[42] H. Adeli, "Neural networks in civil engineering: 1989-2000," Computer-Aided Civil and Infrastructure Engineering, vol. 16, no. 2, pp. 126-142, 2001.

[43] E. B. Baum and D. Haussler, "What size net gives valid generalization?," Neural Computation, vol. 1, no. 1, pp. 151-160, 1989.

[44] M. Neshat, A. Adela, A. Masoumi, and M. Sargolzae, "A comparative study on ANFIS and fuzzy expert system models for concrete mix design," International Journal of Computer Science Issues, vol. 8, no. 2, pp. 196-210, 2011. 


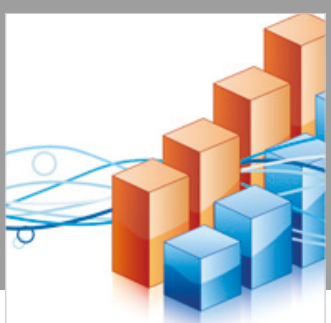

Advances in

Operations Research

\section{-n-m}
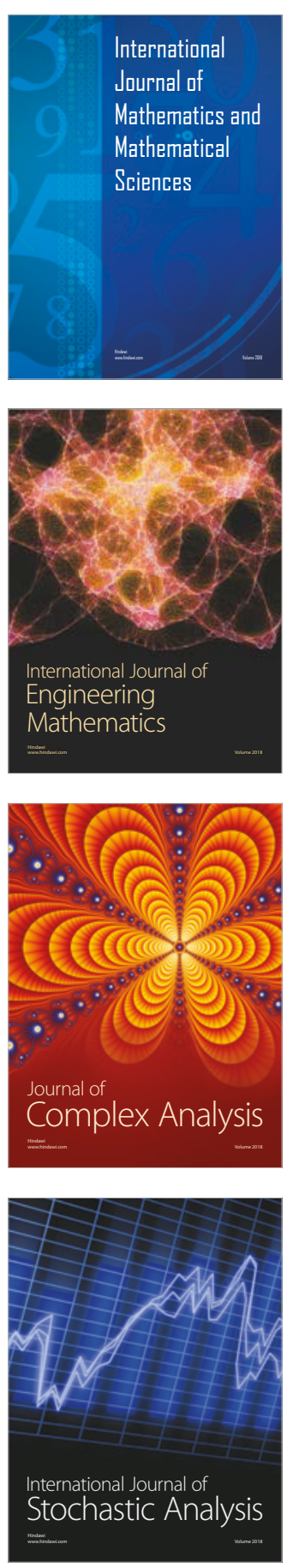
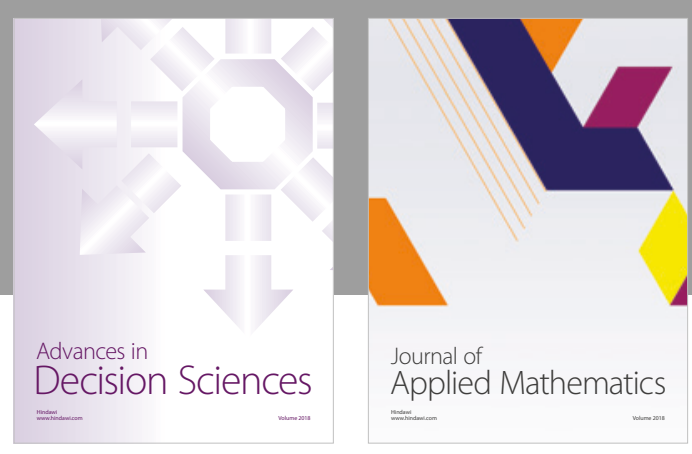

Journal of

Applied Mathematics
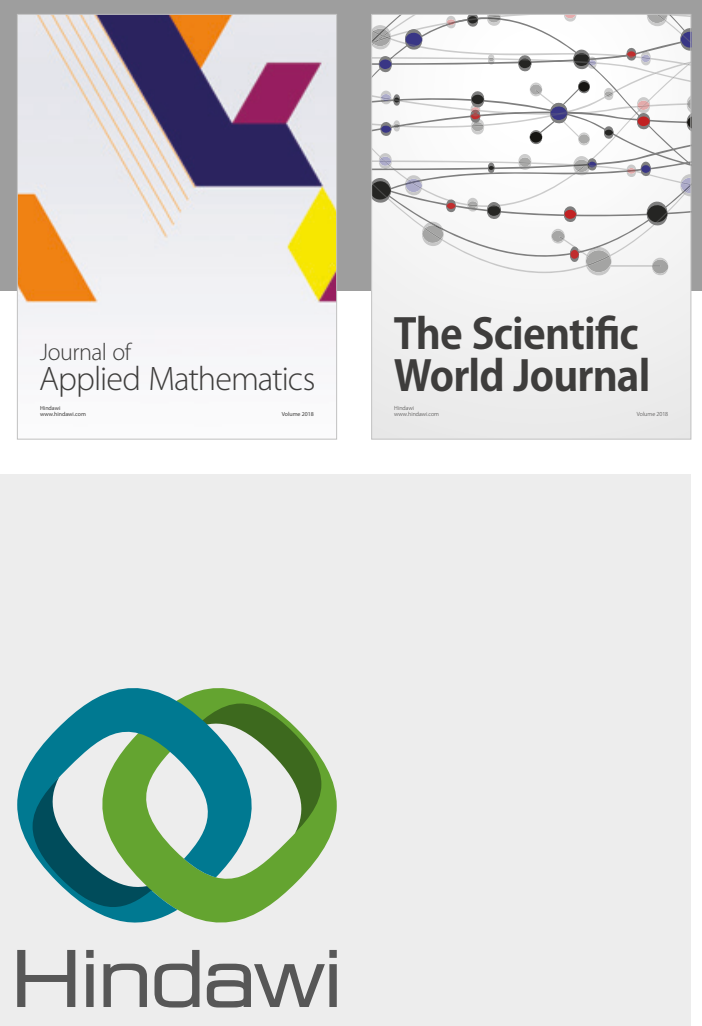

Submit your manuscripts at

www.hindawi.com

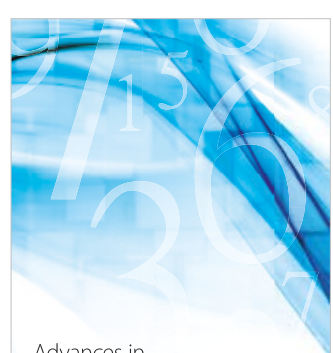

Advances in
Numerical Analysis
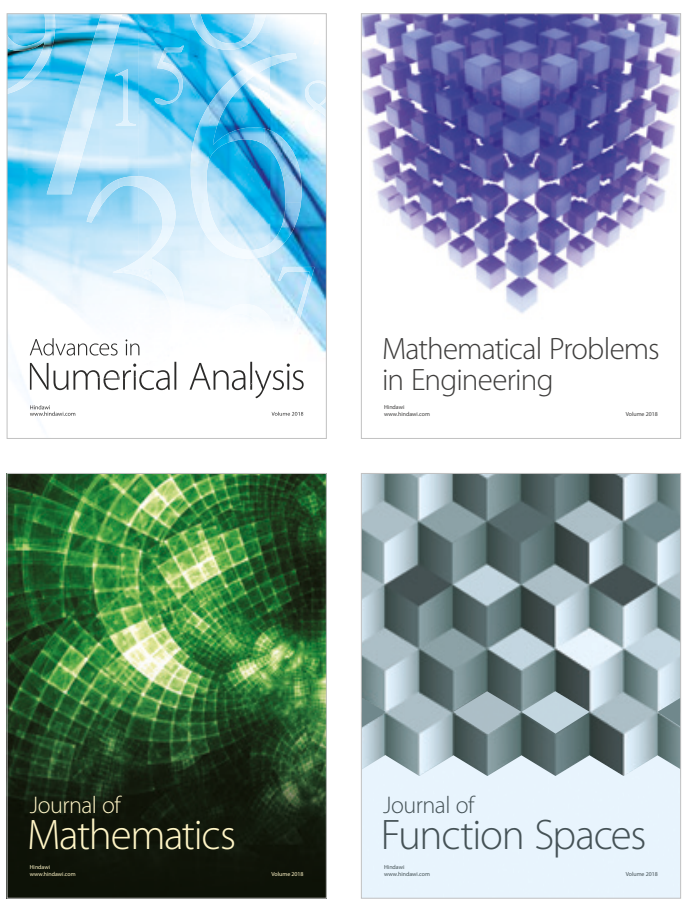

Mathematical Problems in Engineering

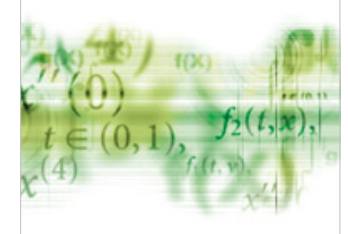

International Journal of

Differential Equations

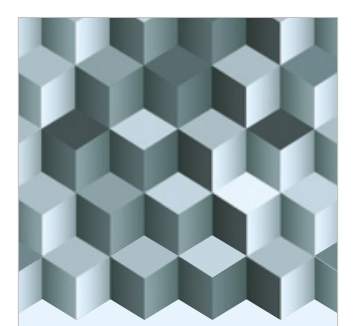

Journal of

Function Spaces
The Scientific

World Journal

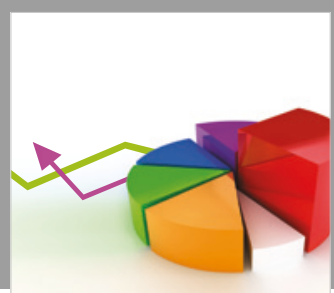

Journal of

Probability and Statistics
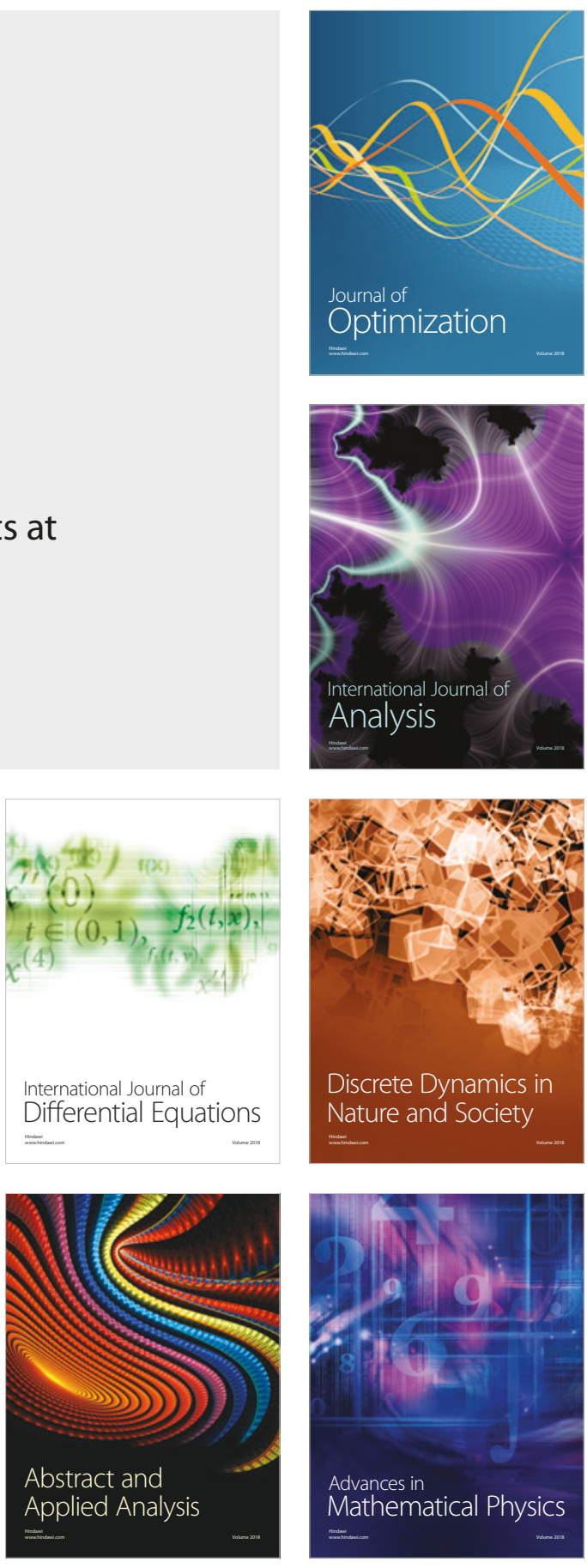